\title{
Investigating Preservice Elementary Teachers' Subject-Specific Self-Efficacy in Teaching Science
}

\author{
Adam Ali Al Sultan ${ }^{1 *}$ \\ ${ }^{1}$ Imam Abdulrahman Bin Faisal University, SAUDI ARABIA
}

Received 14 December 2019 - Accepted 12 February 2020

\begin{abstract}
Self-efficacy plays a key role in determining teaching practices. Still, concerns regarding the low science self-efficacy beliefs held by elementary teachers have raised questions about the effectiveness of teacher preparation programs. Previous research has been restricted to labeling preservice elementary teachers as having high, medium, or low science teaching self-efficacy. Few extended efforts have been made to clearly distinguish preservice elementary teachers' subjectspecific lack of confidence in teaching science. The present study aimed to investigate preservice elementary teachers' subject-specific self-efficacy in teaching science using a mixed-method research design. The participants included 55 preservice elementary teachers at a university in the United States. Quantitative data were collected using the Beliefs About Teaching instrument, and interviews were used to collect qualitative data. The results showed that the participants had the highest self-efficacy level in biology, followed by earth science, chemistry, and physics. Four themes emerged from the participants' reasons for feeling more confident in teaching biology concepts than physics: education experience, teacher experience, subject comprehension, and subject relevance. This study highlights the essential role played by teacher preparation programs in providing ample opportunities for preservice elementary teachers to develop a strong understanding of the content and teaching methods of all science subjects.
\end{abstract}

Keywords: elementary education, preservice teachers, self-efficacy, subject-specific

\section{INTRODUCTION}

Teacher preparation programs around the world strive to ensure that their preservice teachers demonstrate effective instruction. In the context of elementary education, preparing preservice elementary teachers to teach science successfully is a fundamental issue. Elementary preservice teachers are expected to teach all subject areas in their classrooms; therefore, the quality of instruction at the elementary level depends on preparing teachers with appropriate content knowledge and pedagogical skills as well as providing them with positive beliefs about teaching these subjects during their teacher preparation programs. However, several researchers have argued that achieving the necessary content knowledge, pedagogical skills, and positive beliefs toward teaching all subject areas is challenging. For example, Velthuis et al. (2014) asserted that teacher education programs are challenged to prepare their preservice elementary teachers to realize high teaching self-efficacy in all subjects, such as reading, writing, and math. As Bursal (2010) argued, it is highly unlikely that elementary teachers are equally well prepared to feel positive about teaching all subjects areas, especially in the sciences.

The need to identify the specific science subjects (e.g., biology, earth science, chemistry, and physics), which preservice elementary teachers lack confidence in teaching, has emerged from the demands of science education reform. For example, the Next Generation Science Standards (NGSS) is a landmark reform that emphasizes three dimensions to learning science: crosscutting concepts, science and engineering practices, and disciplinary core ideas (NGSS Lead States, 2013). The NGSS highlighted that learners are expected to develop a strong foundation of science content that represents the disciplinary core ideas, which students use in the context of the remaining dimensions. The 


\section{Contribution to the literature}

- Although research in elementary education has acknowledged the importance of self-efficacy, few studies have attempted to distinguish the actual science subjects that preservice elementary teachers' lack confidence in teaching.

- The current study aims to contribute to this growing area of research by investigating preservice elementary teachers' subject-specific self-efficacy in teaching science using a mixed-method research design, which allows for a more comprehensive analysis of the obtained data.

- This study offers four reasons for preservice elementary teachers to feel more confident in teaching biology concepts than physics: education experience, teacher experience, subject comprehension, and subject relevance.

disciplinary core ideas include physical science, life science, earth and space science, and engineering, which are used to construct explanations and as a form of evidence to support arguments (National Research Council, 2012). Such reforms place high demands on elementary teachers because they play a critical role in early science learning and establishing a scientific foundation for students that can enable or constrain them from continuing their learning experience and achieving the goals of science education reform (Schwarz, 2009; Yoon \& Kim, 2016). However, a common challenge for preservice elementary teachers in their future career is their responsibility for teaching the majority of subjects in elementary education. Preservice elementary teachers take relatively few science courses in teacher preparation programs, which may contribute to a lower degree of self-efficacy when it comes to science teaching (Luft, Hill, Nixon, Campbell, \& Dubois, 2015; Wang, Tsai, \& Wei, 2015). Previous research has established that negative beliefs adversely affect preservice elementary teachers' self-efficacy and lead them to avoid teaching science as much as possible or to teach it poorly. With the fixed time that preservice elementary teachers have in teacher education programs to cover a range of subject areas, it is necessary to identify their subject-specific self-efficacy in teaching science and exploring the factors that influenced their beliefs.

Along with this argument, many reports in the literature on preservice elementary teachers' responses have concerned the Science Teaching Efficacy Belief Instrument-Preservice (STEBI-B), which is used to measure science teaching self-efficacy and outcome expectancy in preservice elementary teachers. As a result, most researchers have been restricted to labeling preservice elementary teachers as having high, medium, or low science teaching self-efficacy without providing information on the actual science subjects that preservice elementary teachers lack confidence in teaching. Deehan (2017) conducted a systematic review of literature on the STEBI-B that included an overview of how the instrument is employed methodologically within the literature. However, none of the reviewed research items, including articles, dissertations, and presentations, yielded an approach to identifying preservice elementary teachers' subject-specific selfefficacy in teaching science. For instance, Tosun (2000), who conducted an insightful study to investigate preservice elementary teachers' beliefs toward science and science teaching by examining prior experiences and achievements in science courses, modified the STEBI-B to design a series of semi-structured interview questions to expose the beliefs of preservice elementary teachers concerning science and science teaching. Tosun also used an achievement questionnaire that asked the participants to self-report letter grades for all science subjects pursued in high school and college, including biology, physics, and chemistry. As an example, Tosun reported that $97 \%$ of the participants completed at least one chemistry course in high school, but only $14 \%$ did so in college. Based on this approach, Tosun indicated that the participants had overwhelmingly negative selfefficacy in teaching science and concluded that many students avoid pursuing coursework in science unless it is required by their educational institution. A limitation with this approach is that it does not provide the participants with the opportunity to explain why they chose to avoid coursework in a particular science subject.

Although researchers have acknowledged the importance of the STEBI-B, few have extended their efforts to clearly distinguish preservice elementary teachers' subject-specific lack of confidence in teaching science. Therefore, this study seeks to obtain data that will address this issue by investigating preservice elementary teachers' subject-specific self-efficacy in teaching science using a mixed-method research design. This study thus seeks to answer the following research questions:

1. What are preservice elementary teachers' subjectspecific self-efficacy levels in teaching science?

2. Why do preservice elementary teachers have high or low self-efficacy levels in teaching a specific science subject? 


\section{THEORETICAL FRAMEWORK AND REVIEW OF LITERATURE}

\section{Self-Efficacy}

The theoretical framework of the current study is primarily based on Bandura's (1977) conceptualization of self-efficacy, which is driven by social cognitive theory. According to Bandura (1997), perceived selfefficacy refers to "beliefs in one's capabilities to organize and execute the courses of action required to produce given attainments" (p. 3). This was later conceptualized as an active construct that can change with experience and help individuals to adapt themselves to complex situations (Gist \& Mitchell, 1992).

Bandura (1977) argued that self-efficacy is shaped and influenced by four sources: (a) mastery experience, (b) vicarious experience, (c) verbal persuasion, and (d) emotional arousal. Mastery experiences comprise the most influential source because these experiences provide authentic evidence that a person can succeed in the desired task. Vicarious experiences are also compelling because they involve an individual observing another's performance and gaining confidence from that experience. Verbal persuasion, which is provided by other individuals, can influence a person's confidence either positively or negatively. Finally, emotional arousal, stress, anxiety, or general feelings about a given task can also influence one's belief in one's effectiveness. Along the same lines, TschannenMoran et al. (1998) subsequently argued that self-efficacy beliefs are situational, contextual, and subject-matter specific. A typical example of this view is the elementary teacher who has positive self-efficacy beliefs in teaching subjects such as reading, writing, and math but negative self-efficacy beliefs in teaching science.

Bandura (1986) stated that self-efficacy beliefs consist of two dimensions: outcome expectancy and personal efficacy. Outcome expectancy refers to individuals' beliefs that their behavior will produce desired outcomes, and personal efficacy refers to individuals' confidence in executing actions that result in the achievement of a desired goal. In the context of education, an elementary science classroom teacher might expect that certain actions, such as appropriate instruction, student participation, and hands-on activities, will bring the desired results in student learning (high outcome expectancy). However, the teacher might not have the necessary confidence to execute those actions (low personal efficacy).

As a result of the critical role played by the construct of self-efficacy in determining teaching practices, selfefficacy has attracted a considerable amount of research in science teaching. Several lines of evidence have suggested that teachers with high self-efficacy are committed to teaching science, are more willing to adopt and succeed in implementing inquiry-based practices, and they create a learner-centered environment in their classrooms (Appleton \& Kindt, 2002; Ramey-Gassert, Shroyer, \& Staver, 1996; Riggs \& Enochs, 1990). As such, research on preservice teachers' self-efficacy in teaching science has become a central issue in science education.

\section{Preservice Elementary Teachers' Science Teaching Self-Efficacy}

Researchers have attempted to develop instruments to measure preservice teachers' science teaching selfefficacy to explore this construct in a variety of contexts during their teacher preparation program. The Science Teaching Efficacy Belief Instrument (STEBI) is one of the most common instruments used to measure science teaching self-efficacy. Riggs and Enochs (1990) developed the STEBI, which consists of two subscales: personal science teaching efficacy (PSTE) and science teaching outcome expectancy (STOE). The researchers further developed the STEBI-B, a modification of the STEBI to measure preservice elementary teachers' science teaching self-efficacy. Many studies have acknowledged the high validity and reliability of the STEBI-B, making it a widely accepted instrument in the field of science education (Bleicher \& Lindgren, 2005; Schoon \& Boone, 1998; Settlage, 2000).

Still, concerns regarding the low science self-efficacy beliefs held by elementary teachers have raised questions about the effectiveness of teacher preparation programs. To overcome this issue, most researchers have utilized the STEBI-B to evaluate science content and the methods courses taken by preservice elementary teachers to improve their science teaching self-efficacy. However, research exploring this issue has yielded mixed results. For example, Knaggs and Sondergeld (2015) explored preservice elementary teachers' selfefficacy in a semester-long science content course with purposefully embedded experiences that address selfefficacy, verbal persuasion, and simulated modeling/mastery experiences. They found a significant increase in both subscales of the STEBI-B. Along the same lines, Menon and Sadler (2016) explored the relationship between preservice elementary teachers' science self-efficacy and science conceptual understandings during a physics course. Applying the STEBI-B, the researchers found a statistically significant increase in participants' science self-efficacy beliefs and science conceptual understandings. Menon and Sadler highlighted the importance of designing specialized content courses that bring positive changes in preservice elementary teachers' science self-efficacy beliefs.

In contrast, Hechter (2011) investigated the contextual changes among preservice elementary teachers enrolled in a science teaching methods course. The research applied pre-, post-, and retrospective administrations of the STEBI-B. Hechter reported that increasing the number of postsecondary science courses improved participants' scores only on the PSTE subscale 
of the STEBI-B. The research highlighted the importance of shaping and delivering better and more engaging science courses rather than increasing the quantity of the courses. Similarly, Bleicher and Lindgren (2005) studied the relationship between preservice elementary teachers' science conceptual understanding and science teaching self-efficacy beliefs before and after learning science in a constructivist-oriented methods course. Bleicher and Lindgren utilized the STEBI-B and a science conceptual understanding test as quantitative data sources. Although self-efficacy increased on both scales, the researchers reported no significant relationships between conceptual understanding and outcome expectancy in the pre- or posttest results.

Conflicting results have also been documented in research seeking to improve preservice elementary teachers' science self-efficacy beliefs through practicum courses. For example, McDonnough and Matkins (2010) found that practicum courses positively affected participants' self-efficacy beliefs with regard to teaching science. They measured participants' self-efficacy beliefs using the STEBI-B. The researchers attributed this positive effect to the physiological and emotional comfort the participants gained from their actual interactions with schools and classrooms. However, Ebrahim (2012) explored the impacts of a practicum course on preservice elementary teachers' science teaching self-efficacy by applying the STEBI-B. Ebrahim reported no significant change on either the PSTE or STOE subscales during the time they were enrolled in the teaching practicum course. Ebrahim further stated that the results might be due to the design of the teacher preparation program and methods course.

The research to date on preservice elementary teachers' self-efficacy in teaching science has focused primarily on using the STEBI-B to label preservice elementary teachers as having a range from high to low levels of self-efficacy toward teaching science. Still, researchers have reported concerns regarding preservice elementary teachers' low science self-efficacy; as a result, efforts by researchers were made to improve teacher education programs in general and science and methods courses specifically. However, preexisting low science self-efficacy toward teaching a specific science subject may influence participants' responses to the STEBI-B. For example, a participant may have a high level of selfefficacy in teaching biology concepts but a low level of self-efficacy in physics. As a result, the participants may strongly disagree with the STEBI-B statement, "I know the steps necessary to teach science concepts effectively" in light of their low levels of self-efficacy in teaching physics concepts. A search of the literature revealed that Yilmaz-Tuzun (2008) addressed this issue in the context of elementary education. The researcher developed the Beliefs About Teaching (BAT) instrument to measure preservice elementary teachers' self-efficacy in teaching science concept knowledge in the subjects of biology, earth science, physics, and chemistry. Yilmaz-Tuzun found that participants reported feeling "more confident teaching content in biology, earth science, or both than teaching content in physics, chemistry, or both" (p. 197). Although the study successfully identified the actual science subjects, more data are needed to address the reasons that some preservice elementary teachers feel more confident in teaching a specific science subject than others and vice versa.

\section{MATERIALS AND METHODS}

\section{Research Design}

The current study employed a mixed-method design that is known for having three major design types: exploratory, explanatory, and triangulation (Fraenkel, Wallen, \& Helen, 2012). In the triangulation design, also known as convergent parallel design (Creswell, 2014), both quantitative and qualitative methods are given equal weight to collect data on participants. The two methods are carried out at the same time and then analyzed separately. This design was used because of its ability to determine whether the two methods converge upon a single understanding of the research problem under investigation. As a result, the triangulation design gives an added depth of understanding about the results derived from both the quantitative and qualitative data. In this study, the quantitative part measured preservice elementary teachers' subject-specific self-efficacy in teaching science using the BAT instrument. The qualitative part measured preservice elementary teachers' reasons for their responses using semistructured interviews. Following this, the quantitative and qualitative results were analyzed and compared.

\section{Participants}

Overall, 55 preservice elementary teachers ( 10 men and 45 women) enrolled in a teacher preparation program at a Midwestern university in the United States participated in this study. The program prepared them to teach students in grades one through six. The participants were selected through convenience sampling from two science methods courses offered at the end of the program and before their student teaching course.

\section{Data Sources and Procedures}

In this study, both quantitative and qualitative techniques were used to collect data from the participants. The quantitative data were collected using the BAT. Developed by Yilmaz-Tuzun (2008), the BAT uses a 5-point Likert scale response survey with the following answer options: strongly agree, agree, uncertain, disagree, and strongly disagree. The purpose of the BAT is to measure preservice elementary teachers' 
self-efficacy levels in four areas: assessment techniques, science content knowledge, teaching methods, and classroom management. The science content knowledge section addresses preservice elementary teachers' subject-specific self-efficacy in science teaching and was used in the current study. In this section, the participant is asked to use the 5-point Likert scale to rate their response to the following statement: "Given my current science content knowledge, I believe that I am able to teach thoroughly the following concepts" (p. 201). The participants are also asked to rate their level of selfefficacy in teaching four specific science subjects: (a) biology, including plants, animals, nutrition, living things, and the human body; (b) earth science, including the earth, ecology, weather, the moon system, and the solar system; (c) chemistry, including light, air, water, matter, and atoms; and (d) physics, including sound energy, heat energy, magnetic energy, electrical energy, and simple machines. Yilmaz-Tuzun developed the BAT by examining methods courses at three Midwestern universities in the United States. Then, the researcher piloted the instrument with science methods students at 14 Midwestern universities before finalizing it using a team of experts. Yilmaz-Tuzun reported that Cronbach's alpha reliability coefficient for the BAT was 0.95 .

Regarding the qualitative data, in this study, a semistructured interview was used to collect data face to face. Because of university guidelines, the researcher had limited time to interview the participants. Therefore, 15 participants were selected randomly to eliminate selection bias, and they agreed to be interviewed. An interview guide was developed to help manage and benefit from the limited time available with the participants (Patton, 2015). The interview guide was developed in light of Rubin and Rubin's (2012) recommended procedures. The interview guide consisted of three sections (Appendix). The first section contained warm-up questions, which included three questions aimed to put the interviewer and participant at ease with one another to make the rest of the interview flow more efficiently. The second section contained the main four questions that addressed the current research. The third section contained the three probe questions that helped keep the conversation on target and encouraged the participants to provide more detailed answers. Two science education researchers reviewed the interview guide. Following this, the interview guide was piloted with four preservice elementary teachers who were not participants in the study to gain feedback and estimate the time needed to complete the interviews. On average, the interviews took $15 \mathrm{~min}$ to complete.

Ethical approval was obtained from the university's ethical review board. The participants first responded to the BAT. They were informed about the aim of the study and given instructions on how to complete the BAT. All 55 participants completed the instrument. On the same day, the researcher conducted the interviews. The
Table 1. Descriptive Statistics for the BAT

\begin{tabular}{lcc}
\hline Subject & Mean & SD \\
\hline Biology & 4.29 & 0.42 \\
Earth science & 3.88 & 0.64 \\
Physics & 3.00 & 0.69 \\
Chemistry & 3.34 & 0.49 \\
\hline
\end{tabular}

participants signed consent forms before taking part in the study.

\section{RESULTS}

\section{Preservice Elementary Teachers' Subject-Specific Self-Efficacy}

Table 1 shows the descriptive statistics for the participants' responses to the BAT. The table shows that the participants had the highest level of self-efficacy in teaching biology $(M=4.29, S D=0.42)$ and the lowest self-efficacy level in physics $(M=3.00, S D=0.69)$.

A one-way analysis of variance test was used to look at the differences between the means of self-efficacy for the four science subjects. The test results revealed a statistically significant difference in the self-efficacy of the four science subjects $(p<0.05, F(54.23,71.06)=54.95$, $p=.000)$. Furthermore, a post-hoc Tukey test indicated a significant difference between all the science subjects at $p<0.05$. Therefore, the participants had the highest selfefficacy level in biology, followed by earth science, chemistry, and physics. Table 2 presents the participants' response rate in percentages for each science concept.

The statistics for biology in Table 2 show that most of the participants, ranging from $70.91 \%$ to $100 \%$, strongly agreed or agreed that they are confident in teaching concepts related to plants, animals, living things, and the human body. However, $70.91 \%$ of the participants strongly agreed or agreed that they are confident in teaching nutrition concepts, and $100 \%$ strongly agreed or agreed that they are confident in teaching concepts related to living things. Interestingly, the highest percentage for the "undecided" concepts was for nutrition $(29.09 \%)$. Furthermore, it is important to note that none of the participants disagreed or strongly disagreed about their confidence in teaching any of the biology content.

The next subject was earth science. The participants showed high confidence levels in teaching concepts related to the earth and weather by strongly agreeing or agreeing with the items $(89.09 \%$ and $92.72 \%$, respectively). However, when the participants responded about their confidence level in teaching ecology, moon system, and solar system concepts, a moderate number of participants strongly agreed or agreed that they had confidence in teaching these subjects $(69.09 \%, 65.45 \%$, and $41.81 \%$, respectively). A close inspection of Table 2 shows that $32.73 \%$ of the participants were undecided about their confidence 
Table 2. The Level of Self-Efficacy in Teaching Science Concepts

\begin{tabular}{|c|c|c|c|c|c|c|}
\hline Subject & Concepts & Strongly agree & Agree & Undecided & Disagree & Strongly disagree \\
\hline \multirow[t]{5}{*}{ Biology } & Plants & 38.18 & 54.55 & 7.27 & 0 & 0 \\
\hline & Animals & 41.82 & 54.55 & 3.64 & 0 & 0 \\
\hline & Nutrition & 29.09 & 41.82 & 29.09 & 0 & 0 \\
\hline & Living things & 38.18 & 61.82 & 0 & 0 & 0 \\
\hline & Human body & 45.45 & 49.09 & 5.45 & 0 & 0 \\
\hline \multirow[t]{5}{*}{ Earth science } & The earth & 32.73 & 56.36 & 10.91 & 0 & 0 \\
\hline & Ecology & 20.00 & 49.09 & 27.27 & 3.64 & 0 \\
\hline & Weather & 36.36 & 56.36 & 7.27 & 0 & 0 \\
\hline & Moon system & 25.45 & 40.00 & 20.00 & 10.91 & 3.64 \\
\hline & Solar system & 16.36 & 25.45 & 32.73 & 23.64 & 1.82 \\
\hline \multirow[t]{5}{*}{ Chemistry } & Light & 1.82 & 16.36 & 34.55 & 41.82 & 5.45 \\
\hline & Air & 18.18 & 56.36 & 14.55 & 9.09 & 1.82 \\
\hline & Water & 23.64 & 47.27 & 16.36 & 9.09 & 3.64 \\
\hline & Matter & 14.55 & 45.45 & 21.82 & 12.73 & 5.45 \\
\hline & Atoms & 0.00 & 27.27 & 45.45 & 20.00 & 7.27 \\
\hline \multirow[t]{5}{*}{ Physics } & Sound energy & 1.82 & 18.18 & 34.55 & 29.09 & 16.36 \\
\hline & Heat energy & 0.00 & 27.27 & 38.18 & 21.82 & 12.73 \\
\hline & Magnetic energy & 23.64 & 41.82 & 18.18 & 12.73 & 3.64 \\
\hline & Electrical energy & 0.00 & 20.00 & 25.45 & 40.00 & 14.55 \\
\hline & Simple machines & 18.18 & 38.18 & 20.00 & 12.73 & 10.91 \\
\hline
\end{tabular}

levels in teaching solar system concepts, and $23.64 \%$ disagreed on teaching the same concept.

Regarding the subject of chemistry, Table 2 shows a notable decrease in confidence among the participants compared to their confidence in teaching biology and earth science. Most of the participants, ranging from $18.18 \%$ to $74.54 \%$, strongly agreed or agreed that they are confident in teaching the five chemistry concepts. What is interesting about the data in this section is that a total of $47.27 \%$ strongly disagreed or disagree that they are confident in teaching the concept of light. Additionally, the highest undecided response $(45.45 \%)$ was for the concept of atoms.

As shown in the final section of Table 2, the participants were asked about their confidence levels in teaching physics concepts. The table shows a dramatic decrease in confidence levels compared to those listed in the other sections of the table. Most of the participants, ranging from $20 \%$ to $65.46 \%$, strongly agreed or agree that they are confident in teaching the five physics concepts. An alarming percentage of the participants disagreed or strongly disagreed that they are confidant in teaching electrical energy and sound energy concepts (54.55\% and $45.45 \%$, respectively). Furthermore, the two highest "undecided" responses for teaching were for heat and sound energy $(38.18 \%$ and $34.55 \%$, respectively).

\section{Preservice Elementary Teachers' Interviews}

During the interviews, the majority of the participants stated that they had the highest confidence level in teaching biology and the lowest confidence level in teaching physics. The overall purpose of the interview questions was to identify which science subject the participants felt the most and least confident in teaching and then to investigate their reasons for selecting the two science subjects. Table 3 presents a summary of the participants' responses regarding their confidence levels in teaching the science subjects.

Table 3 shows that $80 \%(N=12)$ of the participants expressed that they felt more confident in teaching biology concepts. The same participants felt less confident in teaching physics concepts. The remaining three participants $(20 \%)$ felt more confident teaching earth science concepts and less confidant in teaching chemistry concepts. In the following paragraphs, the emerging themes will be presented for the $80 \%(N=12)$ of the participants who felt more confident in teaching biology concepts and less confident in teaching physics concepts.

The first theme that emerged from the participants' responses was education experience. The participants emphasized that having more education in the subject of biology than in physics made them more confident in teaching biology concepts. For example, one of the responses was, "I definitely had more schooling in biology" (P5). Another participant stated, "I have learned more about biology during my high school years than physics" (P2). Another respondent stated, "I feel more confident in teaching biology because in high school I took more classes in biology" (P8). Other participants confirmed that they received the least education in physics. For instance, one participant 
Table 3. Participants' Self-Efficacy Levels in Teaching Science Subjects

\begin{tabular}{lcccc}
\hline Confidence level & Biology & Earth science & Chemistry & Physics \\
\hline More confidence & P1, P2, P3, P5, P6, P7, P8, P10, & P4, P9, P15 & None & None \\
Percentage & $80 \%$ & $20 \%$ & & $0 \%$ \\
Less confidence & None & None 12, P13, P14 & P4, P9, P15 & P1, P2, P3, P5, P6, P7, P8, \\
& & & P10, P11, P12, P13, P14 \\
Percentage & $0 \%$ & $0 \%$ & $20 \%$ & $80 \%$ \\
\hline
\end{tabular}

stated, "I had physics before in a science class when I started the program, but I never directly took a physics course" (P6). Another participant was more explicit about their schooling experience, stating, "I didn't really start learning about physics until I got into college" (P11).

Furthermore, evidence of this theme stood out when the participants revealed their concerns about teaching physics because of a lack of education experience. One participant reported a major concern regarding teaching physics without having taken a previous physics course, stating, "I feel the least confident in teaching physics because I never took a physics course before. So, it will be hard to teach something that I haven't learned myself" (P3). A couple of participants expressed their concerns on this theme by stating, "I need to learn more about physics at this stage. I would take more classes or have more information about it" (P12) or "I have more confidence to teach biology than physics mainly because the largest class that I took in high school was in biology" (P14). As a final example, one participant summarized their education experience as follows:

\section{I think the one I feel most confidence in teaching is biology. I think just because it's the one that they teach the most in school. I know in my high school you did not have to take physics. So, I actually never took a physics course except for the basics. So, biology would be the most confident in teaching, and physics would be the least confident in teaching. (P1)}

Taken together, the participants' responses provided important insights on the possible influence of subject matter on self-efficacy.

The second theme derived from the analysis of the interview data was teacher experience. This theme emerged when the participants elaborated on how their education experience allowed them the opportunity to experience different teaching methods and activities applied by their teachers. As a result, the participants' experience with their teachers provided them with the chance to evaluate different teaching methods, which they articulated made them feel more confident in teaching biology concepts. For example, one participant stated about their high school experience, "My teacher used some good ways to teach biology concepts. I will definitely use some of his ways, but not all of them. I will choose what made me understand and leave the rest" (P3). Another participant reported, "The hands-on activities that she did were helpful and made me understand a lot of concepts in biology" (P5). Other participants felt more positive about their experience. For example, one participant stated, "My teacher used so many great ways to teach us biology concepts. I will definitely use them with my students" (P2). Another participant reported, "I really liked how my teacher linked biology to the natural world. I am passionate about teaching and learning biology" (P13). Overall, the participants expressed how beneficial it was for them to evaluate the different teaching approaches and activities applied by their teachers to consider in their future teaching.

The third theme that emerged from the participants' responses was subject comprehension. The participants emphasized that they felt more confident in teaching biology because of the nature of the concepts, which they described as being easier to comprehend than physics and thus easier to teach. For example, one participant stated, "I think that biology is very real and easier to understand" (P5). Another participant explained why biology is easier to understand and therefore easier to teach:

I am most confident in biology. I feel like it is the easiest one to understand and make connections to because a lot of it is stuff you can comprehend. I will not have a hard time teaching biology concepts to my students. (P11)

Another participant supported the theme, stating, "I believe I would be more confident in teaching biology just because it's clear information and easier to remember" (P6). In addition, a couple of participants emphasized that they had "a good understanding" (P1 and P3) of biology, and that is the reason they are more confident in teaching its concepts.

Contrary to this view, the participants had a common view about teaching physics, that it was hard to understand, and they linked it to their low confidence in teaching the subject. A number of participants offered an explanation for their struggle with physics concepts: the mathematical nature of the subject. For example, one 
participant stated, "I am less confident in teaching physics because of the mathematical component, and it's more difficult for me to interpret and it would be hard to teach" (P7). The same concern emerged in many of the participants' responses: "I struggle with physics because of all the math; I struggle with that a lot" (P10) and "I have a hard time understanding physics. It's very abstract, and I have a hard time really understanding math formulas and what exactly they mean" (P14). One participant identified the mathematical challenge by stating, "I don't understand it, the math and numbers. Physics is like a foreign language to me" (P2). Several participants were more explicit in describing this major concern, stating, "I guess, if people bring up physics, I normally do not know what they are probably going to talk about. So, I am going to just exit the conversation" (P8) and "Physics was tough because of the calculations. I just couldn't understand it and had to just memorize everything" (P12). Overall, what stood out from the participants' responses was their concern regarding math as one of the main challenges to comprehending physics concepts and thus teaching those concepts to their future students.

The fourth theme that emerged from the participants responses was subject relevance. They found biology to be related and practical in their everyday encounters and environment, which they say led to their increased confidence in teaching biology concepts compared to teaching physics. For example, a number of participants stated, "I see biology when I look around, living things, animals, and plants. I can't see physics' applications around me" (P1). Another participant reported, "I feel more confident in teaching biology because it's about animals, plants, and all that different kind of stuff that I can encounter in my environment" (P8). One participant provided a broader explanation, stating, "Biology is the world around you; biology is about animals and living things in the area. Having that outdoor experience and being able to interact with the environment makes teaching biology concepts more meaningful" (P7). A couple of participants underlined the relevance of biology concepts to them through the accessibility of outdoor activities in teaching biology concepts. Another participant added, "I find myself in teaching biology because it is related to something that I can connect to; it's about life, and it make more sense to me" (P5). Other participants expressed their concerns about teaching physics concepts because, in their view, physics concepts are not present outside the classroom. For instance, one participant stated, "At the elementary level, I am probably less confident in teaching physics concepts. I am an outdoor enthusiast, and physics is like equations and pencil-and-paper stuff" (P12). Another participant reported, "I would be more confident in teaching biology concepts as a teacher than physics. It's hard for me to take kids outside and show them certain things going on related to physics concepts" (P14).
Finally, the three remaining participants $(\mathrm{P} 4, \mathrm{P} 9$, and P15) reported that they felt more confident in teaching earth science concepts and less confident in teaching chemistry concepts. The three participants revealed that they experienced more education in earth science concepts than in physics. For example, participant (P4) stated, "I don't know much about physics. I learned more about earth science and biology in high school and in my science courses in college, but I feel more confident in teaching earth concepts to children because I better understand earth concepts" Although all three participants specified that they felt less confident in teaching chemistry, they expressed different reasons for choosing chemistry. Participant 4 revealed that her past experience with her chemistry teacher was not successful: "I couldn't understand the many concepts in chemistry; I had a hard time understanding my teachers. The lessons were very abstract." However, participants 9 and 15 argued that the concepts of chemistry depended on memorization, which made them feel less confidant in teaching chemistry concepts. For example, participant 15 stated, "Chemistry is full of symbols and equations that you have to just memorize. I have to memorize so much information about elements and compounds to understand it. So, I don't feel confident in teaching chemistry concepts."

In summary, the qualitative data supported the quantitative statistics. Taken together, these results suggest that the majority of preservice elementary teachers in this study have the highest self-efficacy levels in teaching biology, followed by earth science, chemistry, and physics. Furthermore, the four main reasons for their responses involved their education experiences, teacher experience, subject comprehension, and subject relevance.

\section{DISCUSSION}

The purpose of the current study was to investigate preservice elementary teachers' subject-specific selfefficacy in teaching science using a mixed-method research design. The findings of the study showed that the majority of the participants $(80 \%)$ had the highest self-efficacy level in biology and the lowest in physics. These results are consistent with those of Yilmaz-Tuzun (2008), who reported that preservice elementary teachers had a higher self-efficacy level in teaching biology than physics concepts. The literature review showed that data about preservice elementary teachers' subject-specific self-efficacy in teaching science are limited. The majority of the research relied on the STEBI-B and was restricted to labeling preservice elementary teachers as having either high, medium, or low science teaching selfefficacy. Therefore, the contribution to the literature of the current study emerges from the triangulation of the quantitative and qualitative data results. 
The qualitative data revealed four reasons for the participants' beliefs. The first reason was identified as education experience. The participants highlighted that they had more prior education in the subject of biology than in physics. As a result, they reported having more content knowledge and thus more confidence in teaching biology. The debate among researchers continues about the link between self-efficacy and science content knowledge. This study's findings support those from Menon and Sadler (2016) and Hechter (2011), who reported that prior school science experiences were positively correlated with self-efficacy on the PSTE subscale of the STEBI-B among preservice elementary teachers. Many of the participants in this study indicated they felt less confident in teaching physics because they took few to no physics courses in high school. For example, one participant stated, "I feel the least confident in teaching physics because I never took a physics course before. So, it will be hard to teach something that I haven't learned myself" (P3). Researchers have reported that many students enter college without the content knowledge needed to perform college-level work successfully (Venezia \& Jaeger, 2013). Thus, students may compensate for their insufficiencies by choosing the corresponding college courses. However, elementary teachers are usually generalists, and teacher preparation programs aim to prepare student to effectively teach all subject areas, not just science, and develop pedagogical skills (Carrier, 2009). As a result, teacher preparation programs face the challenge of designing their programs to fit all the demands of different subjects. Evidence obtained in this study suggests that preservice elementary teachers need more content knowledge to build and improve their selfefficacy in teaching specific science subjects. For example, one participant stated, "I need to learn more about physics at this stage. I would take more classes or have more information about it." (P12). Therefore, rather than adding science content and methods courses to an already full teacher education program, existing courses could be supplemented with strategies to help students overcome their lack of confidence in teaching specific science subjects.

The second reason for the participants' high selfefficacy levels in teaching biology and low levels in teaching physics directly emerged from the participants' education experience, referred to in this study as teacher experience. The participants asserted that their education experience allowed them the opportunity to experience teaching methods and activities adopted by their teachers. The notion of passing negative beliefs toward science from teachers to their students is a concerning issue in science education. Researchers have argued that elementary teachers' negative beliefs toward science adversely affect their science teaching selfefficacy. As a result, they overly rely on teacher-directed and text-based instruction (Bursal, 2010). The participants in this study reported positive experiences only with the subject of biology in high school. For example, one participant stated, "My teacher used so many great ways to teach us biology concepts. I will definitely use them with my students" (P2). Therefore, evidence from this study suggests that preservice elementary teachers may hold negative beliefs toward teaching a specific science subject and not all science subjects.

The third reason for the participants' high selfefficacy levels in teaching biology and low levels in teaching physics was subject comprehension. It is important to note that the quantitative findings of this study showed the highest percentage on the BAT for disagreeing and strongly disagreeing on their ability to teach physics concepts involved sound, heat, and electrical energy. These results add to the growing body of evidence that shows the importance of addressing the challenges facing preservice elementary teachers in comprehending the concepts of energy. Diakidoy and Iordanou (2003) indicated that preservice elementary teachers faced several challenges related to the concept of energy, such as the distinction between energy and force. Other researchers provided further evidence that teachers tend to consider energy a material entity rather than an abstract idea and to associate energy primarily with living things (Kruger, Palacio, \& Summers, 1992). The concept of energy has been recognized as a core idea in science education. Recent reforms, such as the framework for K-12 science education (National Research Council, 2012), have identified energy as a core concept in the physical sciences. The concept of energy provides a fundamental framework for interpreting a wide range of phenomena (Arons, 1999).

The qualitative data revealed more insight into the challenges the participants faced in comprehending physics concepts and may provide some explanation for the quantitative data results. Particularly revealing is the fact that the participants mentioned math as a source of difficulty in comprehending physics. The overwhelming majority of participants explicitly referred to math with different words, such as "difficult," "struggle," and "calculations." One participant explicitly referred to math as "a foreign language." According to Pospiech (2008), math plays an important role in physics as a valuable tool that provides the underlying structure of a theory. As such, students rely on rote memorization when lacking the ability to translate between the physical objects with their relations and the mathematical formulas. Talking about this issue, a participant stated, "Physics was tough because of the calculations. I just couldn't understand it and had to just memorize everything" (P12). This argument draws attention to the possibility that preservice elementary teachers may not achieve the appropriate mathematical tools for treating physics contents in teacher education programs. The evidence from this study suggests the 
idea of synchronizing education in mathematics and physics at an appropriate time during teacher preparation programs.

The final reason for the participants' high selfefficacy levels in teaching biology and low levels in teaching physics was subject relevance. The participants clearly expressed that biology concepts were more closely related to their everyday encounters than physics concepts, thus empowering them with the confidence needed to teach biology concepts. As an example, one participant explicitly stated that "having that outdoor experience and being able to interact with the environment makes teaching biology concepts more meaningful to teach." The real relevance of biology concepts was frequently highlighted in the participants' responses through words such as "see," "encounter," "interact," and "accessibility." Compared to physics, the participants shied away from explaining various everyday phenomena from the viewpoint of physics. For instance, one participant stated, "I guess, if people bring up physics, I normally do not know what they are probably going to talk about. So, I am going to just exit the conversation." A possible explanation for this might be related to the preparation of preservice elementary teachers to teach multiple subjects in their important role as scientists. According to Abramzon, Saccoman, and Hoeling (2017), elementary educators generally do not consider themselves scientists as a result of the range of subjects they are required to teach. Additionally, the education that preservice elementary teachers receive in preparation for their careers is typically much different from that of scientists. Therefore, the participants' responses in this study indicated that teacher education programs need to highlight the responsibility that preservice elementary teachers have as scientists and the importance of being well aware of the use of science subjects in everyday life.

Further work is required to investigate the effective ways that science and methods courses in teacher education programs can be utilized to address preservice teachers' low self-efficacy in teaching physics. A further study with greater focus on developing the activities that foster the concept of energy in science courses is therefore suggested. Further research is also suggested to investigate the different approaches in methods courses that feature more integration of the relationship between mathematics and physics.

\section{CONCLUSION}

The purpose of the current study was to investigate preservice elementary teachers' subject-specific selfefficacy in teaching science using a mixed-method research design. The quantitative data showed that the participants had the highest self-efficacy level in biology, followed by earth science, chemistry, and physics. The qualitative data supported the quantitative statistics, and four themes emerged regarding the participants' reasons for feeling more confident in teaching biology concepts than physics concepts: education experience, teacher experience, subject comprehension, and subject relevance.

The evidence from this study suggests that preservice elementary teachers' low self-efficacy beliefs in teaching science may be due to a lack of confidence in teaching a specific science subject rather than science in general. As such, this study is unique in identifying and examining the reasons preservice elementary teachers feel less confident in teaching physics. Taken together, these results suggest that developers of science teaching selfefficacy questionnaires should include items that address subject-specific self-efficacy to address the needs of preservice elementary teachers to become more confident in teaching science. Another recommendation driven by the findings of this study is that developers of science and methods courses in teacher preparation programs should supplement their curricula with lessons and activities that foster students' confidence in teaching a specific science subject rather than redesigning the entire course.

Several limitations must be noted regarding the present study. Time limitations with the participants resulted in a couple of restrictions. First, the number of interviewees willing to contribute to this study was limited to 15 . Second, the available time with the participants only allowed the researcher to interview them about the science subjects they felt the most and least confident in teaching. As such, future research is suggested to allow participants to elaborate on all the science subjects. Overall, this study highlights the essential role that teacher preparation programs play in providing ample opportunities for students to develop a strong understanding of the content and teaching methods of all science subjects to help them feel more confident in their future science teaching.

\section{REFERENCES}

Abramzon, N., Saccoman, S., \& Hoeling, B. (2017). Improving the attitude of pre-service elementary school teachers towards teaching physics. International Journal of Elementary Education, 6(3), 1623. https:/ / doi.org/10.11648/j.ijeedu.20170603.11

Appleton, K., \& Kindt, I. (2002). Beginning elementary teachers' development as teachers of science. Journal of Science Teacher Education, 13(1), 43-61. https://doi.org/10.1023/A:1015181809961

Arons, A. (1999). Development of energy concepts in introductory physics courses. American Journal of Physics, 67, 1063-1067. https://doi.org/10.1119/ 1.19182

Bandura, A. (1977). Self-efficacy: Toward a unifying theory of behavioral change. Psychological Review, 
84(2), 191-215. https://doi.org/10.1037/0033295X.84.2.191

Bandura, A. (1986). Social foundations of thought and action: A social cognitive theory. Prentice-Hall.

Bandura, A. (1997). Self-efficacy: The exercise of control. Freeman

Bleicher, R., \& Lindgren, J. (2005). Success in science learning and preservice science teaching selfefficacy. Journal of Science Teacher Education, 16(3), 205-225. https://doi.org/10.1007/s10972-0054861-1

Bursal, M. (2010). Turkish preservice elementary teachers' self-efficacy beliefs regarding mathematics and science teaching. International Journal of Science and Mathematics Education, 8(4), 649-666. https://doi.org/10.1007/s10763-0099179-6

Carrier, S. (2009). The effects of outdoor science lessons with elementary school students on preservice teachers' self-efficacy. Journal of Elementary Science Education, 21(2), 35-48. https://doi.org/10.1007/ $\mathrm{BF} 03173683$

Creswell, J. (2014). Research design: Qualitative, quantitative, and mixed methods approaches (4th ed.). SAGE.

Deehan, J. (2016). The science teaching efficacy belief instruments (A and B): A comprehensive review of methods and findings from 25 years of science education research. Berlin: Springer International Publishing. https://doi.org/10.1007/978-3-319-42465-1_2

Diakidoy, I., \& Iordanou, K. (2003). Preservice teachers' and teachers' conceptions of energy and their ability to predict pupils' level of understanding. European Journal of Psychology of Education, 18(4), 357-368. https:/ / doi.org/10.1007/BF03173241

Ebrahim, A. (2012). The self-efficacy of pre-service elementary teachers in Kuwaiti science programs. Education, 133(1), 67-76.

Fraenkel, J., Wallen, N., \& Helen, H. (2012). How to design and evaluate research in education (8th ed.). McGrawHill.

Gist, M., \& Mitchell, T. (1992). Self-efficacy: A theoretical analysis of its determinants and malleability. Academy of Management Review, 17(2), 183-211. https:/ / doi.org/10.2307/258770

Hechter, R. (2011). Changes in preservice elementary teacher's personal science teaching efficacy and science teaching outcome expectancies: The influence of context. Journal of Science Teacher Education, 22(2), 187-202. https://doi.org/10.1007/ s10972-010-9199-7

Knaggs, C., \& Sondergeld, T. (2015). Science as a learner and as a teacher: Measuring science self-efficacy of elementary preservice teachers. School Science and
Mathematics, 115(3), 117-128. https://doi.org/ 10.1111/ssm.12110

Kruger, C., Palacio, D., \& Summers, M. (1992). Surveys of English primary teachers' conceptions of force, energy, and materials. Science Teacher Education, 76(4), 339-351. https://doi.org/10.1002/sce. 3730760402

Luft, J., Hill, K., Nixon, R., Campbell, B., \& Dubois, S. (2015). The knowledge needed to teach science: Approaches, implications, and potential research. Paper presented at the annual meeting of ASTE, Portland, OR.

McDonnough, J. T., \& Matkins, J. J. (2010). The role of field experience in elementary pre-service teachers' self-efficacy and ability to connect research to practice. School Science and Math., 110(1), 13-23. https:// doi.org/10.1111/j.1949-8594.2009.00003.x

Menon, D., \& Sadler, T. D. (2016). Preservice elementary teachers' science self-efficacy beliefs and science content knowledge. Journal of Science Teacher Education, 27(6), 649-673. https:/ / doi.org/10.1007/ s10972-016-9479-y

National Research Council. (2012). A framework for K-12 science education: Practices, crosscutting concepts, and core ideas. National Academies Press.

Next Generation Science Standards Lead States. (2013). Next generation science standards: For states, by states. National Academies Press.

Patton, M. (2015). Qualitative research \& evaluation methods: Integrating theory and practice (4th ed.). SAGE.

Pospiech, G. (2008). Mathematical constructs in the physical reality. Interdisciplinary Educational Research in Mathematics and Its Connections to the Arts and Sciences, 5(1), 233-240.

Ramey-Gassert, L., Shroyer, M., \& Staver, J. (1996). A qualitative study of factors influencing science teaching self-efficacy of elementary level teachers. Science Education, 80(3), 283-315. https://doi.org/ 10.1002/(SICI)1098-237X(199606)80:3<283::AIDSCE2>3.0.CO;2-A

Riggs, I., \& Enochs, L. (1990). Toward the development of an elementary teacher's science teaching efficacy belief instrument. Science Education, 74(6), 625-637. https://doi.org/10.1002/sce.3730740605

Rubin, H. J., \& Rubin, I. S. (2012). Qualitative interviewing: The art of hearing data (3rd ed.). SAGE.

Schoon, K., \& Boone, W. (1998). Self-efficacy and alternative conceptions of science of preservice elementary teachers. Science Education, 82(5), 553568. https:// doi.org/10.1002/(SICI)1098-237X (199809)82:5<553::AID-SCE2>3.0.CO;2-8

Schwarz, C. (2009). A learning progression of elementary teachers' knowledge and practices for model-based 
scientific inquiry. Paper presented at the annual meeting of the American Educational Research Association, San Diego, CA. https://doi.org/ 10.1002 / sce. 20324

Settlage, J. (2000). Understanding the learning cycle: Influences on abilities to embrace the approach by preservice elementary school teachers. Science Education, 84(1), 43-50. https://doi.org/10.1002/ (SICI)1098-237X(200001)84:1<43::AID-SCE4>3.0.C $\mathrm{O} ; 2-\mathrm{F}$

Tosun, T. (2000). The beliefs of pre-service elementary teachers toward science and science teaching. School Science and Mathematics, 100(7), 374-379. https:/ / doi.org/10.1111/j.19498594.2000.tb18179.x

Tschannen-Moran, M., Hoy, A., \& Hoy, W. (1998). Teacher efficacy: Its meaning and measure. Review of Educational Research, 68(2), 202-248. https://doi.org/10.3102/00346543068002202

Velthuis, C., Fisser, P., \& Pieters, J. (2014). Teacher training and pre-service primary teachers' selfefficacy for science teaching. Journal of Science
Teacher Education, 25(4), 445-464. https:/ / doi.org/10.1007/s10972-013-9363-y

Venezia, A., \& Jaeger, L. (2013). Transitions from high school to college. The Future of Children, 23(1), 117136. https://doi.org/10.1353/foc.2013.0004

Wang, Y., Tsai, C., \& Wei, S. (2015). The sources of science teaching self-efficacy among elementary school teachers: A mediational model approach. International Journal of Science Education, 37(14), 2264-2283. https://doi.org/10.1080/09500693. 2015.1075077

Yilmaz-Tuzun, O. (2008). Pre-service elementary teachers' beliefs about science teaching. Journal of Science Teacher Education, 19(2), 183-204. https://doi.org/10.1007/s10972-007-9084-1

Yoon, H., \& Kim, B. (2016). Preservice elementary teachers' beliefs about nature of science and constructivist teaching in the content-specific context. Eurasia Journal of Mathematics, Science and Technology Education, 12(3), 457-475. https:/ / doi.org/10.12973/eurasia.2016.1210a

\section{APPENDIX}

\section{Interview Guide}

\section{Approximately $15 \mathrm{~min}$}

Warm-up questions:

1. Hello, [participant's name]. My name is [researcher's name], and I would like to ask you some questions related to the field of elementary education. Would this be okay?

2. What year of college are you in?

3. Which science classes have you taken in the program?

Main questions:

1. Which of the following science subjects do you feel most confidence in teaching: physics, chemistry, biology, or earth science?

a. Please explain why and give some examples to support your answer.

b. Describe your feelings when asked to teach this subject in your future classroom.

2. Did you have any positive experiences with the subject in high school? If yes, describe your experience. If no, proceed to the next question.

3. Which of the following science subjects do you feel most confident in teaching: physics, chemistry, biology, or earth science?

a. Please explain why and give some examples to support your answer.

b. Describe your feelings when asked to teach this subject in your future classroom.

4. Did you have any negative experiences with the subject in high school? If yes, describe your experience. If no, proceed to the next question.

Probes:

1. That's interesting. Can you tell me more about that?

2. Do you have some specific instances in mind, or are you speaking in general?

3. Can you elaborate more on that?

\section{http://www.ejmste.com}

